$($ AUC $=0.716 ;$ specificity, 76.84\%; sensitivity, 66.28\%). Poor validity evidence was observed for pain (AUC $=0.608$; sensitivity, 37.93\%; specificity, 83.74\%) and RTW domains (AUC $=0.534$; sensitivity, $18.99 \%$; specificity, 88.56\%). The RTW domain presented with good reliability (Chronbach $\alpha=0.847)$. The Pain domain could not be described as reliable (Chronbach $\alpha=0.039$ ).

Conclusions As a risk screening tool the CCT-R currently presents with discernible deficiencies relating to its measurement properties in two of the three domains. To facilitate early intervention decision management, CCT-R mental health scores could be useful, while pain and RTW domains require further revision.

\section{IMPROVING ESTIMATES OF THE COSTS OF INJURY IN WESTERN AUSTARLIA USING LINKED DATA}

'Delia Hendrie, ${ }^{1,2}$ Ted Miller, ${ }^{1}$ Sean Randall, ${ }^{1}$ Kate Brameld. ${ }^{1}$ Centre for Population Health Research, Curtin University Perth; ${ }^{2}$ Pacific Institute for Research and Evaluation, Maryland US

\subsection{6/injuryprev-2016-042156.1036}

Background Previous estimates of the costs of injury in Australia have relied heavily on secondary data, including from international sources. The availability of linked health data and other relevant datasets such as police reports of road crashes and personal injury motor vehicle insurance claims data has provided the opportunity to produce Australian-based estimates of the cost of injury using improved methods.

Methods A retrospective, population-based design was adopted in the study. Health data including emergency department presentations, hospital admissions and death data were linked with police crash report records and motor vehicle personal injury claims data by the Data Linkage Branch at the West Australian Health Department for 2002 through to 2014. Episodes of injury were determined using the linked health data, with clear zones established to account for return visits for the same injury. Corresponding injury costs were estimated based on generalised linear modelling of component costs of the injury claims data, with quality of life loss calculated from Global Burden of Disease disability weights.

Results Problems encountered in regards to the identification of episodes of injury will be discussed, in particular in regard to establishing clear zones. Similarly, issue in modelling from injury claims data for road injury casualties to all injury case will be highlighted. Previous estimates of the costs of injury will be compared with estimates based on the linked data approach and difference explored. Trends in injury costs in Western Australia over the past 10 -years will be analysed by socio-demographic and injury characteristics.

Conclusions Injuries are known to impose a significant health and social burden on individuals, families and the community. Applying improved methods of estimating these costs will provide the basis for better policy, planning and targeting of injury prevention strategies.

\section{REGIONAL DIFFERENCES IN SAFETY BEHAVIOUR AND ENVIRONMENTAL SAFETY, FINLAND 2013-2015}

Satu Helakorpi, Oona Pentala, Timo Koskela, Jukka Murto. National Institute for Health and Welfare (THL), Finland

10.1136/injuryprev-2016-042156.1037
Background Local authorities need a health and well-being monitoring system, that gives information on current safety behaviour and environmental safety and changes in them.

Methods The study is based on a nationally and regionally representative cross-sectional questionnaire (postal or web) survey entitled "The Regional Health and Well-being Study" (ATH) carried out in 2013-2015 in Finland. Respondents aged 20 years or more ( $n=89779$ ) were included. The indicators used were: 1 ) use of helmet always when cycling, and 2) slippery footpaths in winter near of respondents' home bother the respondents. Prevalence estimates with $95 \%$ confidence intervals were calculated. The results were presented by different population groups.

Results There were considerable differences in safety behaviour between educational groups, and they were most often unfavourable for the less-educated groups. These differences could generally be observed also at regional level. Use of helmet when cycling was most common in the highest educational group among both men and women. In the region of Uusimaa about $35 \%$ of cyclists reported always wearing a helmet when cycling whereas in Western Finland the corresponding prevalence was about $15 \%$. Slippery footpaths in winter were most common in the region of Uusimaa where over half of respondents reported that slippery footbaths bothered them, compared to $40 \%$ in Central and South-Eastern Finland.

Conclusions There were regional differences in both safety behaviour and environmental safety. In safety behaviour there were also sociodemographic differences. The ATH -study provides local authorities with the necessary tools to monitor their residents' health and well-being together with the factors affecting them. It is also an important tool for the monitoring of safety behaviour and environmental safety and their long- and shortterm changes in the adult population. The results are reported in an interactive online service (in Finnish): www.thl.fi/ath.

\section{FACTORS ASSOCIATED WITH MAXILLOFACIAL FRACTURES IN HASSAN DISTRICT, SOUTH INDIA: A RETROSPECTIVE STUDY}

${ }^{1}$ Utkarsha Lokesh, ${ }^{2}$ Shishir Kamath. 'Rajivgandhi Health University, Karnataka, India; ${ }^{2}$ Rajivgandhi Health University, Karnataka, India

\subsection{6/injuryprev-2016-042156.1038}

Background Injuries are the major public health problem in India. The present study was conducted to assess the aetiology, prevalence and pattern of facial fractures amongst the treated cases of maxillofacial fractures at the trauma centres in Hassan District, South India.

Methods Retrospective data of three years, 2011to 2014 was collected from records of five trauma-treating centres of a Hassan District in Southern India. Age, sex, aetiology, location of fractures and various other variables were collected.

Results Total 208 patients were treated in the hospitals for facial bone fractures. Men were more affected than women with a male to female ratio of $6: 1$. Nearly $50 \%$ of patients were aged between 21-30 years and road traffic injuries $(62.85 \%)$ caused most of the fractures, mostly among non-helmet two wheeler users. Road traffic injuries causing facial fractures occurred predominantly on weekdays (Tuesday and Wednesday). Chi-square test was used to test for significance and a $\mathrm{p}$-value $<0.05$ is regarded as significant. $60.35 \%$ of patients had fractures of mandible followed by $24.85 \%$ of zygomatic bone and $5.31 \%$ of maxillary bone. 
Conclusions This study has shown that road traffic Injuries are responsible for most of the maxillofacial fractures. Non-helmet usage among two wheeler users being the most common factor, which needs to be addressed through education and enforcement.

\section{CHALLENGES IN INJURY DATA ENTRY MANAGEMENT IN LOW RESOURCE SETTINGS - EXPERIENCES FROM BANGLADESH}

Afrida Unjum, Jahangir Hossain, Saidur Rahman Mashreky, Fazlur Rahman, Aminur Rahman. Centre for Injury Prevention and Research, Bangladesh

\subsection{6/injuryprev-2016-042156.1039}

Background Centre for Injury Prevention and Research, Bangladesh (CIPRB) is a leading research organisation in Bangladesh which works with different health related data since 2005. Since its inception, CIPRB developed over 25 different data bases mostly on injury prevention. CIPRB also managed surveillance databases with sample around 1,000,000. There are lots of challenges during data entry using hard copy data collection forms.

Objective The objective of the study was to describe the challenges those were faced during management of data entry in a low resource setting, Bangladesh.

Methodology Since 2005 Centre for Injury Prevention and Research, Bangladesh (CIPRB) has been implementing several research programs. CIPRB established a data entry centre in Dhaka with around 30 data enterers. Before starting data entry all hard copy questionnaires were collected and stored in a store room then the data enterers entered injury data manually in a software. The data entry process was closely monitored under the supervision of a statistician. On completion of entry each data-sets was cleaned for analysis.

Results Computers used for data entry were old versioned and unupgraded. Unstable power supply interrupted data entry process. Maintaining network and server system is expensive and time consuming. Frequent damage of the computer sometimes caused loss of entered data. Poor storage system also caused data loss. Missing and confusing unclear data delays entry process. Data entry became slower in the evening than in the morning time. Due to unavailability of spear computers sometimes data enterers needed to wait until fixation of the broken computer.

Conclusion A lot of challenges were identified, which were mostly due to financial constraints. These challenges are common in the low- and middle-income countries. During research funding donors should support to improve the data entry process which will eventually help to conduct better research.

Acknowledgement Centre for Injury Prevention and Research, Bangladesh (CIPRB)

\section{INNOVATIONS IN HOSPITAL-BASED PARTNERSHIPS IN SAFETY AND INJURY PREVENTION: DEVELOPING INTERDEPARTMENTAL COLLABORATIONS}

Helen Arbogast, Santiago Chambers. Children's Hospital Los Angeles

10.1136/injuryprev-2016-042156.1040

Background Injury prevention professionals are part of a complicated system that works collectively to address injury prevention through development, implementation, participation in and evaluation of an injury prevention program. While the responsibilities of an Injury Prevention Manager (IPM) are vast, and often accompanied by minimal support or funding - the need for extensive reach of injury prevention programs remain. Understanding the causes for injury and prevention frameworks, theories, curriculum development, evaluation, research and program implementation are critical for both the departments success in addressing injury prevention and safety campus-wide.

Methods We conducted a gap analysis of safety and injury prevention measures in the hospital to include internal/external outreach and educational needs, programmatic capacity and staffing deficits. We determined the parameters of injury prevention manager's and safety officer's roles in cross fertilisation and involvement in activities based on a review of national norms, focus groups and key informant interviews. We also convened hospitalbased taskforce and community stakeholders to refine the roles and scope of injury prevention priorities for the hospital.

Results Based on these findings, program priorities were set to reflect the following:

- Develop innovative approaches utilising non-traditional partnerships and networks;

- Engage Office of Safety and Security to participate in related trainings and obtain required certifications in injury prevention;

- Collaborate with the Office of Safety and Security on injury prevention internal activities to include patient safety measures (child passenger safety), staff safety, (seat belt and pedestrian safety) and environmental modifications/ enhancements to improve safety/injury prevention capacity (resources, trainings)

- Develop new systems to provide childhood safety information to patients and families;

- Develop creative strategies and partnerships to address resource gaps that will provide program support externally

Conclusions While the Injury Prevention Manager is responsible for developing, implementing and identifying injury prevention programming for patients, families and community; we believe that enhancing injury prevention occurs through sharing best practices and programs and building meaningful partnerships to sustain programmatic reach, establish policy and practice and improve patient and community education. Unfortunately, the impact/reach of these internal partnerships are often limited to hospital-based initiatives if external/community-based priorities unsupported. Elevating the magnitude and critical nature of injury prevention through interdepartmental engagement to secure ongoing support are among the highest priorities for injury prevention managers, particularly trauma centres.

The unique partnership with the Injury Prevention Department and Office of Safety and Security yielded significant outcomes for both the hospital and community-at-large. As a result, more than 8 members from both departments have successfully completed reciprocal trainings to work in concert as Child Passenger Safety Technicians and in disaster training and response to improve the health and safety of patients and families in the community. This interdepartmental collaboration has yielded more than 25 community-based events, 3 internal hospital policies, 6 certification courses and more than 60,000 contacts. Both areas have fully immersed activities and policies to support this partnership long-term. 